\title{
Aumento na Produção de Ácido Clavulânico com o uso de Quorum Sensing
}

\author{
Gracindo. A ${ }^{1}$, Santos. D. Z. T. ${ }^{1}$, Fonseca. G. A. ${ }^{1}$, Pedrolli. D. B. ${ }^{1}$, Cerri, M. O. ${ }^{1}$. \\ ${ }^{1}$ Universidade Júlio de Mesquita Filho (UNESP), Departamento de Bioprocessos e \\ Biotecnologia. \\ E-mail para contato: marcel@fcfar.unesp.br
}

\begin{abstract}
RESUMO - O aumento da resistência bacteriana a antibióticos vem trazendo cada vez mais preocupação para a área da saúde, portanto, fica mais evidente a necessidade de pesquisas voltadas para essa área a fim de solucionar tal problema. Trabalhos voltados para a produção de ácido clavulânico são de extrema importância nesse quesito, já que este metabolito, produzido pela bactéria Streptomyces clavuligerus, tem a capacidade de auxiliar na eficiência de antibióticos $\beta$-lactâmicos. Com esse projeto objetiva-se obter uma otimização na produção de ácido clavulânico com o uso de quorum sensing que nada mais é que uma comunicação celular entre microrganismos a partir de moléculas sinais, onde as concentrações de tais moléculas são utilizadas para quantificar as concentrações de outros organismos presentes no meio. Assim, essa técnica, pode trazer vantagens a um microrganismo, como a produção de antibiótico para o prevalecimento de uma única espécie. O efeito quorum sensing pode estimular Streptomyces clavuligerus a produzir mais antibióticos na presença dessas moléculas sinais. Para isso será necessário primeiramente realizar o cultivo de $S$. clavuligerus com amostra estéreis de solo, possibilitando analisar se alguma dessas moléculas vão causar interferência, ou seja, aumento na produção de ácido clavulânico.
\end{abstract}

\section{INTRODUÇÃO}

O ácido clavulânico (AC) é um metabólico secundário (caracterizado como uma vantagem ao microrganismo) produzido pelas bactérias Streptomyces clavuligerus, uma bactéria filamentosa aeroestrita. O AC é utilizado para otimizar antibióticos que possuem o anel $\beta$-lactâmico, tais como a penicilina. A ação do composto se baseia na quebra de uma enzima presente nos microrganismos resistentes aos antibióticos, essa enzima é denominada $\beta$-lactamase. A enzima $\beta$-lactamase seria responsável por quebrar o anel $\beta$-lactâmico do antibiótico causando assim a sua ineficiência, porém com a ação do AC de degradar essa enzima, o antibiótico não sofre danos, podendo assim atuar na morte do microrganismo (Nurmohamadi et al., 2014).

Quorum sensing (QS) pode ser entendido como uma comunicação celular feita através de moléculas sinalizadoras, ocorrem tanto em bactérias gram-negativas como em grampositivas. (Decho et al., 2005).

Nas bactérias gram-positivas o QS ocorre usando modificações em oligopeptídeos como molécula sinal e uma cadeia de fosforilação como receptor em outra célula. O que ocorre é 
que as moléculas sinais são produzidas e após eliminadas para o meio externo, quando sua concentração atinge um limite, uma quinase presente na membrana celular consegue captá-las fosforilando o próximo componente (uma proteína reguladora) no ambiente interno celular. Essa proteína tem a capacidade de se ligar ao DNA regulando sua expressão. Desse modo a bactéria consegue ativar genes necessários a partir do QS, ou seja, da concentração de microrganismos a sua volta. (Galloway et al., 2005).

A produção de AC ocorre nas bactérias na fase estacionaria, ou seja, quando a densidade populacional atingiu um equilíbrio, nesse momento os microrganismos já começam a ter a necessidade de disputar a fonte de alimento, ou seja, de energia. Nesse ponto a capacidade de produzir antibióticos se torna vantajosa, já que nesse momento eles começam a ser liberados para eliminar espécies que não possuem resistência, diminuindo assim a competição entre espécies. (Nurmohamadi et al., 2014). Esse projeto tem como principal função a utilização de QS para se obter uma maior produção de AC.

\section{MATERIAIS E MÉTODOS}

\subsection{Preparo dos Meios de cultura}

Para cultivo do microrganismo $S$. clavuligerus foi utilizado o meio de cultura de reativação proposto por Rosa et al. (2005). Já o meio de cultura de crescimento teve a mesma composição do meio de cultura de produção. Ambos foram baseados no meio proposto por Teodoro et al. (2006). $\mathrm{O}$ pH de todos os meios foi ajustado para 6,8 e esterilizado em autoclave a $121^{\circ} \mathrm{C}$ por 20 minutos.

O meio de cultura de reativação (Rosa et al, 2005) é composto por $15 \mathrm{~g} / \mathrm{L}$ de glicerol; $10 \mathrm{~g} / \mathrm{L}$ de peptona bacteriológica; $10 \mathrm{~g} / \mathrm{L}$ de extrato de malte; $1 \mathrm{~g} / \mathrm{L}$ de extrato de levedura; 21 $\mathrm{g} / \mathrm{L}$ de tampão MOPS; $2,5 \mathrm{~g} / \mathrm{L}$ de $\mathrm{K}_{2} \mathrm{HPO}_{4} ; 0,75 \mathrm{~g} / \mathrm{L}$ de $\mathrm{MgSO}_{4} .7 \mathrm{H}_{2} \mathrm{O}$ e $1 \mathrm{~mL} / \mathrm{L}$ de solução de sais.

Já o meio de crescimento e de produção são iguais, ambos propostos por Teodoro et al (2006). Temos como composição desse meio $15 \mathrm{~g} / \mathrm{L}$ de glicerol; $20 \mathrm{~g} / \mathrm{L}$ de isolado proteico de soja; $21 \mathrm{~g} / \mathrm{L}$ de tampão MOPS; $0,8 \mathrm{~g} / \mathrm{L}$ de $\mathrm{K}_{2} \mathrm{HPO}_{4} ; 0,75 \mathrm{~g} / \mathrm{L}$ de $\mathrm{MgSO}_{4} .7 \mathrm{H}_{2} \mathrm{O}$ e $1 \mathrm{~mL} / \mathrm{L}$ de solução de sais.

\subsection{Testes Realizados}

Ao longo do projeto já foram realizados 3 ensaios. Em todos eles foram necessários obter uma solução de água com terra estéril, nos dois primeiros testes eram realizados a filtragem utilizando o filtro analítico e uma bomba a vácuo da solução com terra com que posteriormente foram autoclavados a $121^{\circ} \mathrm{C}$ por 20 min obtendo assim uma solução estéril. No último teste (teste 3), foram realizados os mesmos passos iniciais, mas ao invés de autoclavar a solução no final, foi feita uma filtragem em filtro de 0,22 micrometros para torna-la estéril. 
No primeiro teste foi feita uma solução de 0,1 grama de terra por $\mathrm{mL}$ de água como solução A1 e a partir dessa solução foram realizadas diluições de 1/10 (solução B1), 1/100 (solução C1) e 1/500 (solução D1) e com essas soluções foram realizados os cultivos de $S$. clavuligerus junto com um cultivo normal (solução P1) sem a presença de terra para analisar a interferência da solução estéril de terra na produção de AC.

No segundo teste foi feita uma solução de 0,2 grama de terra por $\mathrm{mL}$ de água como solução A2 e a partir dessa solução foram realizadas diluições de 1/10 (solução B2), 1/100 (solução C2) e 1/500 (solução D2) e com essas soluções foram realizados os cultivos de $S$. clavuligerus junto com um cultivo normal (solução P2) sem a presença de terra para analisar a interferência da solução estéril de terra na produção de AC.

E por fim no último teste (teste 3) foi realizado um cultivo de 0,2 grama de terra por $\mathrm{mL}$ de água que ao invés de autoclavar foi realizado a filtragem em filtro de 0,22 micrometros e um cultivo normal (sem terra), pois assim seria possível analisar se autoclavando o meio estaríamos prejudicando as moléculas presentes e diminuindo a produção de AC.

Todos os cultivos foram realizados em Erlenmeyer de $250 \mathrm{~mL}$ com um volume útil de $10 \%$, ou seja, $25 \mathrm{~mL}$ de meio de cultura. Onde o meio de reativação foi inoculado e deixado em um shaker por 24 horas a $30^{\circ} \mathrm{C}$ e $250 \mathrm{rpm}$, para que após $2,5 \mathrm{~mL}$ fossem passadas para o meio de crescimento que permaneceu mais 24 horas em shaker a $30^{\circ} \mathrm{C}$ e $250 \mathrm{rpm}$ e por último $2,5 \mathrm{~mL}$ fossem transferidas para o meio de produção sendo mantida no shaker por 72 horas a $28^{\circ} \mathrm{C}$ e $250 \mathrm{rp}$. Todas os ensaios foram realizados em duplicadas e as suas análises também foram feitas em duplicatas, portanto, ao fim foram obtidos valores em quadruplicata e com isso tornou-se possível avaliar melhor os resultados obtidos. Por fim amostras do meio de cultura foram centrifugadas a $3720 \mathrm{rpm}$ a uma temperatura de $4^{\circ}$ por $15 \mathrm{~min}$, para que assim ocorre a separação das células e do AC, sendo que o nosso produto de interesse permaneceu no sobrenadante (composto extracelular). Após realizado todos esses procedimentos, foi realizada a análise de concentração de AC por método de espectrofotométrico proposto por Bird et al. (1982) utilizando o reagente imidazol e fazendo a leitura de absorbância à $311 \mathrm{~nm}$ em cubetas de quartzo. A partir da absorbância foi possível obter a concentração de AC com o uso da equação 1 obtida pela curva de calibração de ácido clavulânico.

Absorbância $=0,0204[A C]$

\section{RESULTADOS E DISCUSSÕES}

\subsection{Teste 1}

Após realizado todos os procedimentos do primeiro foi obtido os valores da tabela 1 e a figura 1 para a produção de AC. 
Tabela 1. Tabela com os valores obtidos de AC do teste 1.

\begin{tabular}{ccccc}
\hline $\begin{array}{c}\text { Diluição da } \\
\text { solução A }\end{array}$ & Amostra & \begin{tabular}{c} 
Concentração de terra $\begin{array}{c}\text { Concentração AC } \\
(\mathrm{g} / \mathrm{mL})\end{array}$ \\
\hline-
\end{tabular} $\mathrm{A}^{\mathrm{mg} / \mathrm{L})}$ & $\begin{array}{c}\text { Produção } \\
\text { Normalizada }\end{array}$ \\
\hline $1 / 10$ & $\mathrm{~B} 1$ & 0,1 & 407,1 & 2,00 \\
$1 / 100$ & $\mathrm{C} 1$ & 0,009 & 237,7 & 1,17 \\
$1 / 500$ & $\mathrm{D} 1$ & 0,0009 & 306,4 & 1,50 \\
- & $\mathrm{P} 1$ & 0 & 248,5 & 1,22 \\
\hline
\end{tabular}

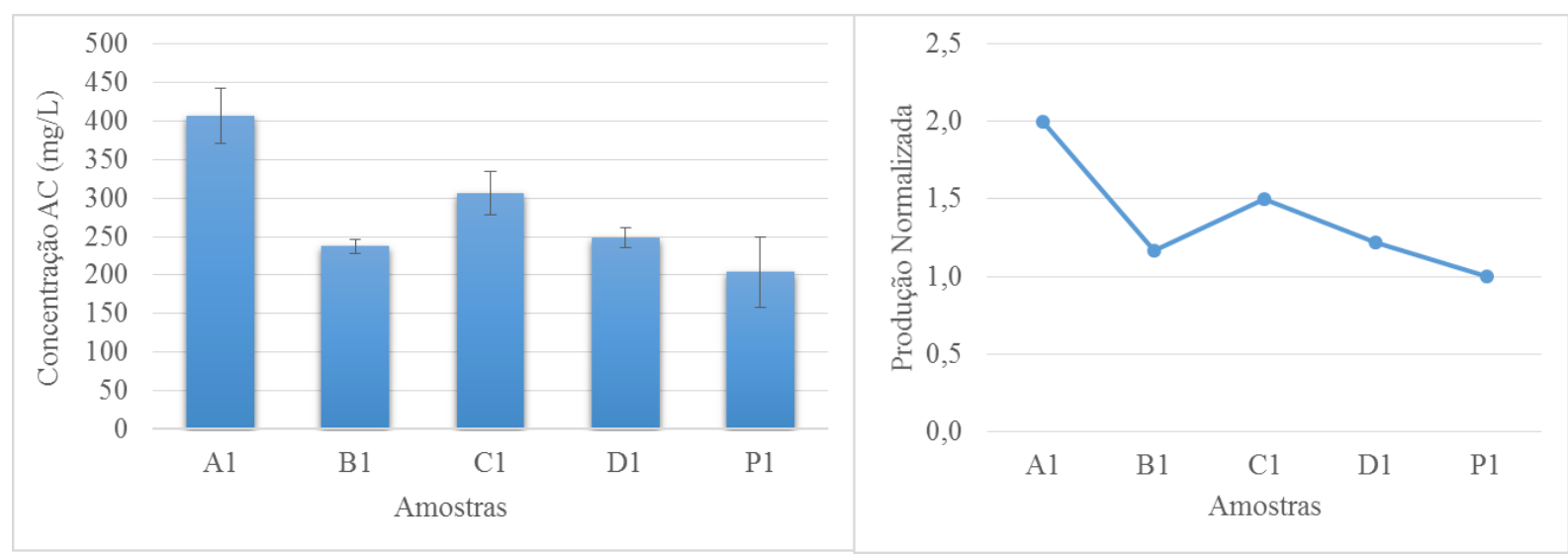

Figura 1. A esquerda encontra-se um gráfico demonstrando a concentração de AC obtida no teste 1. Na direita é possível verificar a produção normalizada do teste 1 .

Com a análise desses valores foi possível observar grande aumento na produção de AC com o uso de $0,1 \mathrm{~g} / \mathrm{mL}$ de terra (aumento de $2 \mathrm{x}$ do que o meio P1). Com isso foi decidido aumentar a concentração máxima de terra para $0,2 \mathrm{~g} / \mathrm{mL}$ para que fosse possível testar como a produção foi afetada nessa nova concentração (teste 2 ).

\subsection{Teste 2}

Após realizado todos os procedimentos do primeiro foi obtido os valores da tabela 2 e a figura 2 para a produção de AC.

Tabela 2. Tabela com os valores obtidos de AC do teste 2 .

\begin{tabular}{ccccc}
\hline $\begin{array}{c}\text { Diluição da } \\
\text { solução A }\end{array}$ & Amostra & $\begin{array}{c}\text { Concentração de } \\
\text { terra }(\mathrm{g} / \mathrm{mL})\end{array}$ & $\begin{array}{c}\text { Concentração AC } \\
(\mathrm{mg} / \mathrm{L})\end{array}$ & $\begin{array}{c}\text { Produção } \\
\text { Normalizada }\end{array}$ \\
\hline- & $\mathrm{A} 2$ & 0,2 & 740,4 & 1,7 \\
$1 / 10$ & $\mathrm{~B} 2$ & 0,018 & 299,5 & 0,7 \\
$1 / 100$ & $\mathrm{C} 2$ & 0,0018 & 269,6 & 0,6 \\
$1 / 500$ & $\mathrm{D} 2$ & 0,00036 & 579,1 & 1,3 \\
- & $\mathrm{P} 2$ & 0 & 438,5 & 1,0 \\
\hline
\end{tabular}



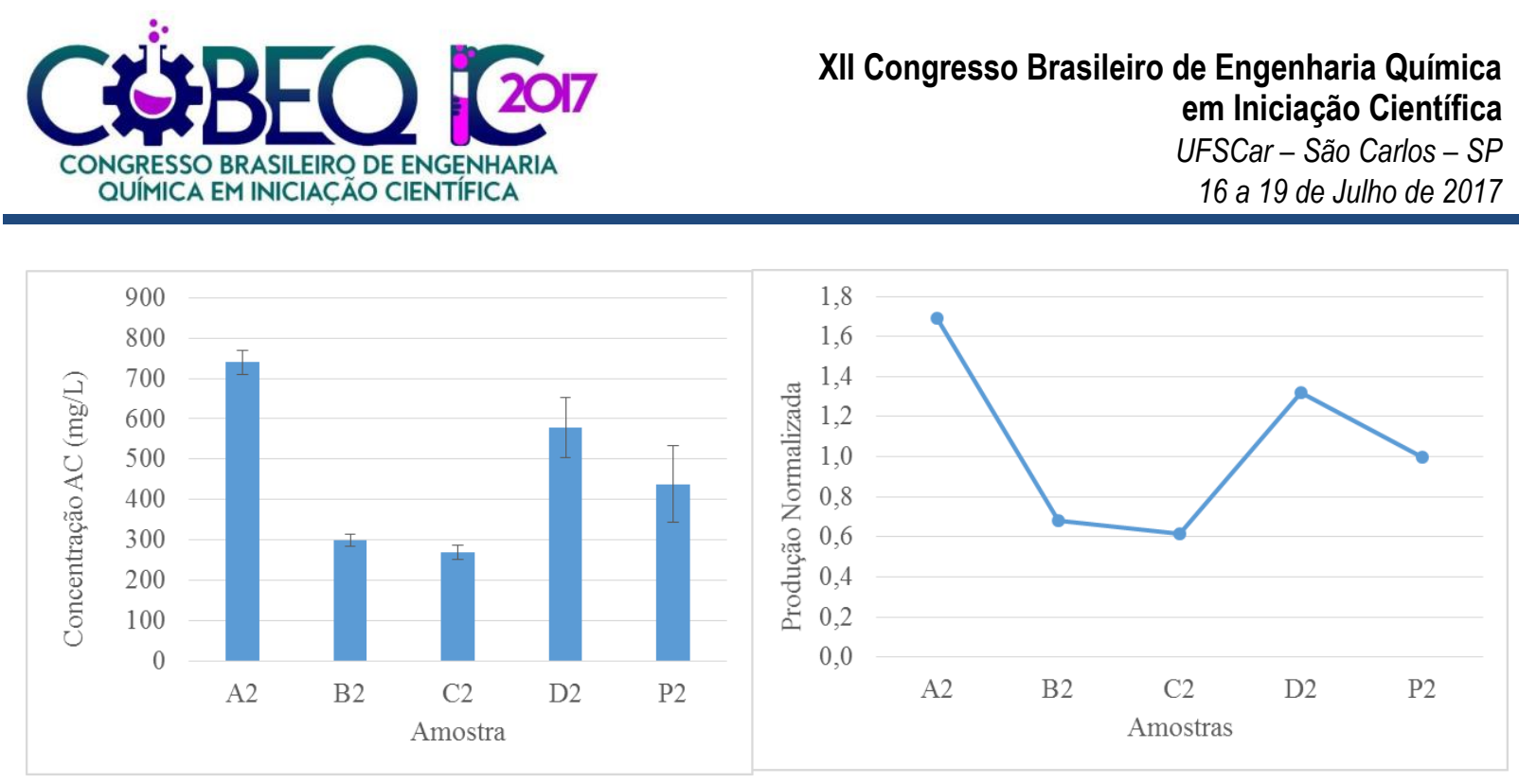

Figura 2. A esquerda encontra-se um gráfico demonstrando a concentração de AC obtida no teste 2. Na direita é possível verificar a produção normalizada do teste 2.

Analisando o teste 2 foi possível confirmar que a maior produtividade ocorreu com a concentração de $0,2 \mathrm{~g} / \mathrm{mL}$ de terra, já que esta apresentou uma produção 1,7 vezes maior que a produção isenta de terra (solução P2).

\subsection{Teste 3}

Após realizado todos os procedimentos do primeiro foi obtido os valores da tabela 3 e a figura 3 para a produção de AC.

Tabela 3. Tabela com os valores obtidos de AC do teste 3.

\begin{tabular}{ccc}
\hline Amostra & $\begin{array}{c}\text { Concentração } \\
\text { AC }(\mathrm{mg} / \mathrm{L})\end{array}$ & $\begin{array}{c}\text { Produção } \\
\text { Normalizada }\end{array}$ \\
\hline Terra $(0,2 \mathrm{~g} / \mathrm{mL})$ & 474,8 & 1,5 \\
Normal (s/ terra) & 323,0 & 1,0 \\
\hline
\end{tabular}

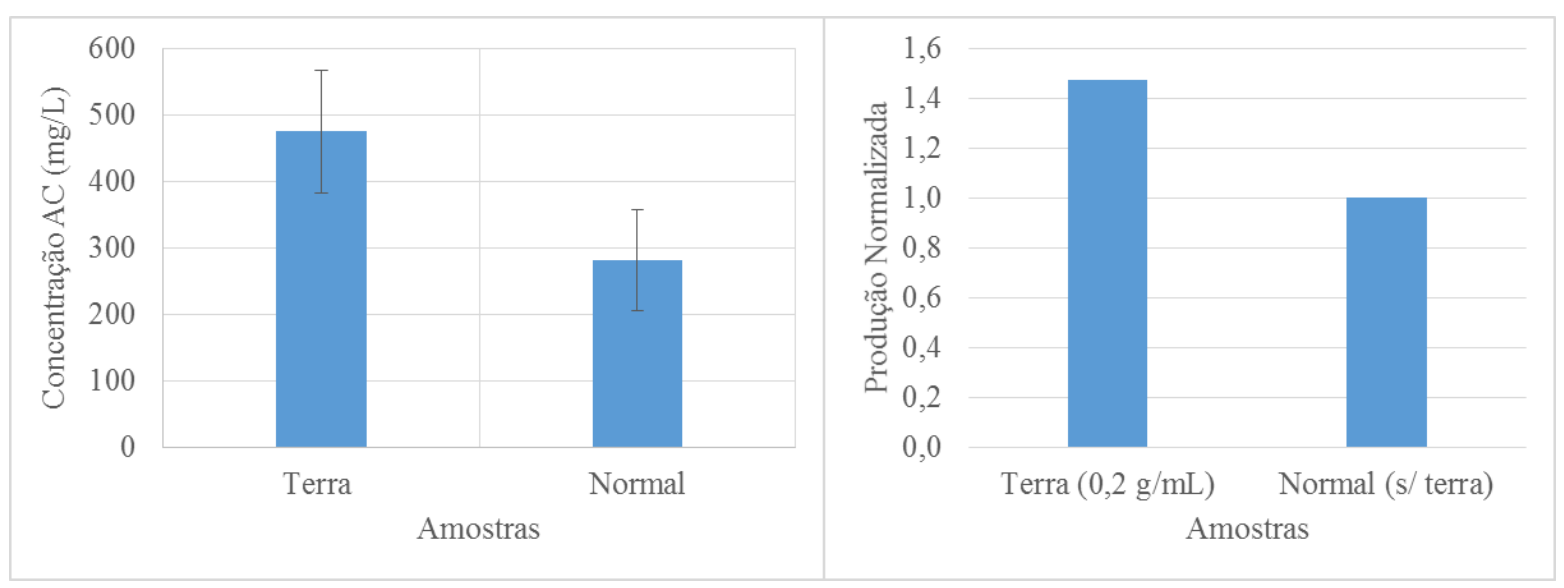

Figura 3. A esquerda encontra-se um gráfico demonstrando a concentração de AC obtida no teste 3. Na direita é possível verificar a produção normalizada do teste 3. 
Fazendo algumas analises no teste 3 , foi possível observar que a produção de AC também teve um aumento significativo quando foi realizado o cultivo em uma solução de terra a $0,2 \mathrm{~g} / \mathrm{mL}$ sem autoclavar, já que nesse caso foi realizada a filtração com o filtro 0,22 micrometros para esteriliza-la.

\section{CONCLUSÃO}

Observando os valores obtidos para a produção de AC em todos os cultivos pode-se perceber que a inserção de terra no meio de cultivo em todos os casos aumentou a quantidade de AC produzida. Em relação ao teste 3 o cultivo com $0,2 \mathrm{~g} / \mathrm{mL}$ de terra produziu 1,47 vezes mais que o cultivo normal (sem terra), entretanto no teste 2 o cultivo com $0,2 \mathrm{~g} / \mathrm{mL}$ de terra (solução A2) produziu 1,7 vezes mais que o cultivo padrão sem a terra (P2), isso quer dizer que a solução A2 (teste 2) foi a que demonstrou maior produtividade, mostrando que apenas autoclavando o meio para torna-lo estéril foi mais eficaz. Pode-se dizer que esse fato ocorreu por causa do filtro usado do teste 3 (filtro de 0,22 micrometros), muito provavelmente o filtro impediu a passagem de células, mas também das moléculas sinais que atuariam no quorum sensing, mostrando ser ineficiente nesse projeto.

Em relação ao quorum sensing, tudo indica que o aumento na produção de AC foi devido a interação do microrganismo S. clavuligerus com as moléculas sinais presentes no meio (quorum sensing), entretanto, o projeto ainda está nas etapas inicias, portanto ainda são necessários novos testes que possam confirmar de fato a sua ocorrência.

\section{REFERÊNCIAS}

BIRD, A.E.; BELLIS, J.M.; GASSON, B.C. Spectrophotometric assay of clavulanic acid by reaction with imidazole. Analyst, v.107, p.1241-1245, 1982.

DECHO A.W.; NORMAN R.S.; VISSCHER P.T. Quorum sensing in natural environments: emerging views from microbial mats. Cell. Trends in Microbiology Vol.18 No.2, p.73-80, 2005

GALLOWAY W.R.J.D.; HODGKINSON J.T.; BOWDEN S.; WELCH M.; SPRING R. Applications of small molecule activators and inhibitors of quorum sensing in Gram -negative bactéria. Cell. Trends in Microbiology September, Vol. 20, No. 9, p.449-458, 2012.

NURMOHAMADI M.; POURGHASSEM H. Clavulanic acid production estimation based oncolor and structural features of streptomycesclavuligerus bacteria using self-organizing mapand genetic algorithm. Elsevier. Computer methods and programs in biomedicine 11 4, p.337-348, 2014.

ROSA, J.C.; BAPTISTA NETO, A.; HOKKA, C.O.; BADINO, A.C. Influence of dissolved oxygen and shear conditions on clavulanic acid production by Streptomyces clavuligerus, Bioproc Biosyst Eng, v.27, p.99-104, 2005.

TEODORO, J.C.; BAPTISTA-NETO, A.; CRUZ-HERNÁNDEZ, I.L.; HOKKA, C.O.; BADINO-JR, A.C. Influence of feeding conditions on clavulanic acid production in fed-batch cultivation with medium containing glycerol, Appl Microbiol Biotechnol, v. 72, p.450-455, 2006. 